\title{
Dissimilar Welding of Superduplex Stainless Steel/HSLA Steel for Offshore Applications Joined by GTAW
}

\author{
Bravo Ivan Mendoza ${ }^{1}$, Zepeda Cuauhtemoc Maldonado ${ }^{1}$, Hernandez Apolinar Albiter², \\ Piedras Eduardo Robles ${ }^{3}$ \\ ${ }^{1}$ Instituto de Investigaciones Metalúrgicas-UMSNH, Morelia Michoacán, México \\ ${ }^{2}$ Instituto Mexicano del Petróleo, México, D. F., México \\ ${ }^{3}$ Instituto Nacional de Investigaciones Nucleares, La Marquesa, Ocoyoacac, México \\ E-mail: ivanmendozabravo@gmail.com \\ Received January 15, 2010; revised March 2, 2010; accepted March 13, 2010
}

\begin{abstract}
The dissimilar metal weld is demanding as well as the similar weld, however, dissimilar weld is more complex than similar weld due to the necessity of being applied in zones where a requirement is to improve some properties. In this work the main purpose is to know the mechanical behavior of a dissimilar weld between HSLA Steel and Superduplex Stainless Steel (SDSS) to establish if the joint is feasible or not. The alloys were welded with GTAW process using a 60-deg and 90-deg single-V groove test specimens in order to observe the effect of the weld pass. The filler metal was chosen with the aid of Schaeffler diagram. It was found that the ER 25.10.4L filler metal provided the best equilibrium between ferrite and austenite phase in the Superduplex Stainless Steel final microstructure and a band of martensite in the HSLA steel final microstructure. The dissimilar joint presented acceptable mechanical properties which are superior to the HSLA in the as-received condition, but lower than the SDSS in the as-received condition, proving that the filler metal was the adequate.
\end{abstract}

Keywords: Superduplex Stainless Steel, API X-52, GTAW, Dissimilar Welding, Pipeline

\section{Introduction}

The oil, gas and petrochemical industries have been using API X52 pipes and other similar materials for offshore and onshore applications [1,2]. An important application of the API X-52 pipe is the exploitation and transportation of the hydrocarbons by Risers. However, the Riser has shown corrosion problems in the splash zone, especially three meters above and three meters below of the sea level. Sea water and tides cause cycles of wetting and drying on the Riser, promoting corrosion and therefore the failure of the pipeline. Currently, the Mexican Petroleum Industry has been using two solutions for this problem: 1) cathodic protection and 2) a carbon steel sleeve; however, both of them need permanent inspection and maintenance [3]. SDSS has an excellent combination of mechanical properties and corrosion resistance [4,5], making it suitable for applications with possibility of corrosion promoted by sea water [6-8], thus, other possible solution for this problem could be substituting the API X-52 pipe of the splash zone with this superduplex stainless steels (SDSS).

Conventional arc welding process can be used to weld SDSS very easily when the parameters are the adequate to maintain the austenite/ferrite balance in the welding metal. However, the most important weldability problems of SDSS are the changes in the austenite/ferrite balance that can affect the ductility if the ferrite percentage is bigger than austenite, and promote the precipitation of intermetallic phases such as sigma phase which affect the corrosion resistance and toughness in the duplex stainless steels $[9,10]$. On the other hand the API $\mathrm{X}-52$ is also affected by the welding process but less than SDSS. To minimize these effects, is important to make a careful selection of welding materials and welding variables $[9,11,12]$. Barnhouse et al., studied dissimilar duplex stainless steel SAF 2205/carbon steel ASTM-A36 weld joint, by means of gas tungsten arc welding (GTAW) and evaluating two filler metals, finding that the filler metal ER 2209 increases the ferrite number in the duplex stainless steel and forms a martensite band on the fusion boundary[11]. This band present solidification pattern type II which was explained by Nelson et al., [13]. 
Keeping in mind those results, the purpose of this investigation was established, therefore the first goal was to select the filler metal to maintain the microstructure balance in SDSS and second, to study the effects of the welding designs and the filler metal to determine the mechanical properties and microstructural changes of dissimilar SDSS 2507/API X52 weld joints.

\section{Experimental Procedure}

To select the filler metal to employ in the dissimilar metal welding (DMW), two filler metals were considered ER 25.10.4L and ER 2209, with the aim of analyzing their effects on the microstructure using the WRC-1998 diagram developed by Kotecki which considers the martensite boundary in the dissimilar metal joining and provides more accurate information [14]. The application of this analysis was done considering the dilution at $50 \%$ on both filler metals. The chemical compositions of the alloys are shown in Table 1 and were determined by optical emission spectrometry (OES) and the nitrogen content was determined by gas analysis.

The base materials employed API X-52 steel and SAF 2507 SDSS were supplied in pipe shape seamless with internal diameter of $101.6 \mathrm{~mm}$ (4 in) and nominal thickness of $6.35 \mathrm{~mm}$ (0.25 in). The pipes were cut into pieces of $100 \mathrm{~mm}$-length and each section was machined with a 30-deg bevel to result in a 60-deg angle in the single $\mathrm{V}$ groove butt joint. Other pipe sections were prepared with a 45-deg bevel to produce a 90-deg groove angle.

The GTAW process was chose because of the flexibility to be used in field applications which are one necessity in the petrochemical industry. Table 2 shows the welding parameters. The welding was performed by a qualified welder.

The samples for the base metal microstructural characterization were cut from the pipes in sizes of $25.4 \mathrm{~mm}^{2}$. The cross sections of each combination of both dissimilar metal welding were removed. All the samples were polished using progressively diamond pastes of 6,3 and $1 \mu \mathrm{m}$. The etching of API X-52 was carried out with Nital $(100 \mathrm{~mL}$ of ethyl alcohol and $2 \mathrm{~mL}$ of nitric acid) and SAF 2507 SDSS was etched with Beraha reagent $(0.7 \mathrm{~g}$
$\mathrm{K}_{2} \mathrm{~S}_{2} \mathrm{O}_{5}, 20 \mathrm{~mL} \mathrm{HCl}, 80 \mathrm{~mL} \mathrm{H} \mathrm{H}_{2} \mathrm{O}$ ). The optical examinations were done through a Nikon Epiphot 300 microscope. Figure 1 shows the microstructure of the base materials.

\section{Results and Discussions}

\subsection{Filler Metal Selection}

Figure 1 shows the API X-52 and SAF 2507 SDSS microstructures in the as-received condition. The base metal SAF 2507 SDSS contains 53\% ferrite and 49\% austenite with a standard deviation of $+/-2.5 \%$; the API X-52 presents $84.47 \%$ ferrite and $14.37 \%$ pearlite with a standard deviation of $+/-2 \%$.

The filler metals ER 2209 DSS and ER 25.10.4L SDSS both were selected due to their chemical compositions which promote ferrite/austenite transformation. Therefore the filler metal has to keep the equilibrium between those phases during the fast cooling typical of the welding process. For this work, WRC-1992 diagram modified was selected due to accuracy to predict the microstructure of the dissimilar metal welding, specially the transition region between the weld metal and API X-52 [15]. This diagram was developed by Kotecki for alloys with $1 \% \mathrm{Mn}$ as is shown in Figure 2. The analysis started with the calculus of the $\mathrm{Cr}_{\mathrm{eq}}$ and $\mathrm{Ni}_{\mathrm{eq}}$ for each alloy using the chemical composition in Table $\mathbf{1}$ and the equations proposed on this diagram.

Once this was done, the first step was to localize the coordinates corresponding to the parent metals in the diagram which are intersected by a line.

The middle point of this line could represent the join of both parent metals in equal quantities, such as in the practice, where the filler metal should be added to these alloys, which is represented by a tie line between each filler metal and the middle point. The prediction of the microstructure for the dissimilar metal welding with the filler metal ER 2209 is expected to have an 8 and $13 \mathrm{FN}$ with $50 \%$ and $25 \%$ of dilution respectively, both having a primary ferrite solidification.

The prediction of the microstructure for the dissimilar metal weld using ER 25.10.4L, showed an 18 and $10 \mathrm{FN}$

Table 1. Chemical composition of the base metal and filler metals (wt.\%).

\begin{tabular}{cccccccccccccccccc}
\hline & $\mathrm{Cr}$ & $\mathrm{Ni}$ & $\mathrm{Mo}$ & $\mathrm{Mn}$ & $\mathrm{Si}$ & $\mathrm{C}$ & $\mathrm{N}$ & $\mathrm{S}$ & $\mathrm{P}$ & $\mathrm{Fe}$ & $\mathrm{Cu}$ & $\mathrm{W}$ & $\mathrm{V}$ & $\mathrm{Nb}^{2}$ & $\mathrm{Cr}_{\text {eq }}$ & $\mathrm{Ni}_{\text {eq }}$ \\
\hline API X 52 & 0.043 & 0.065 & 0.021 & 1 & 0.241 & 0.201 & - & 0.007 & 0.011 & 98.09 & 0.149 & 0.004 & 0.061 & 0.015 & 0.074 & 7.13 \\
SAF 2507 & 25.86 & 7.4 & 4.27 & 0.42 & 0.353 & 0.019 & 0.27 & 0.002 & 0.021 & 63.12 & 0.117 & 0.030 & 0.056 & 0.008 & 30.13 & 13.94 \\
$\begin{array}{r}\text { ER } \\
\text { 25.10.4L }\end{array}$ & 21.72 & 7.32 & 3 & 0.509 & 0.49 & 0.060 & 0.20 & 0.005 & 0.024 & 66.17 & 0.267 & 0.038 & 0.198 & 0.019 & 24.73 & 13.48 \\
ER 2209 & 19.98 & 7.73 & 4.14 & 1.27 & 0.457 & 0.090 & 0.15 & 0.011 & 0.020 & 66.54 & 0.359 & 0.032 & 0.111 & 0.015 & 24.13 & 13.37 \\
\hline
\end{tabular}


Table 2. GTAW parameters.

\begin{tabular}{ll}
\hline \multicolumn{2}{c}{ GTAW PARAMETERS } \\
\hline Polarity & DCEN \\
Welding current & $110 \mathrm{~A}$ \\
Voltage & $10 \mathrm{~V}$ \\
Welding speed & $1.16 \mathrm{~mm} / \mathrm{sec}$ \\
Shielding/Backing Gas & Argon $100 \%$ \\
Interpass temperature & $85^{\circ} \mathrm{C} \mathrm{max}$. \\
Heat input & $0.75 \mathrm{~kJ} / \mathrm{mm}$ \\
Filler metal diameter & $2.4 \mathrm{~mm}$ \\
\hline
\end{tabular}

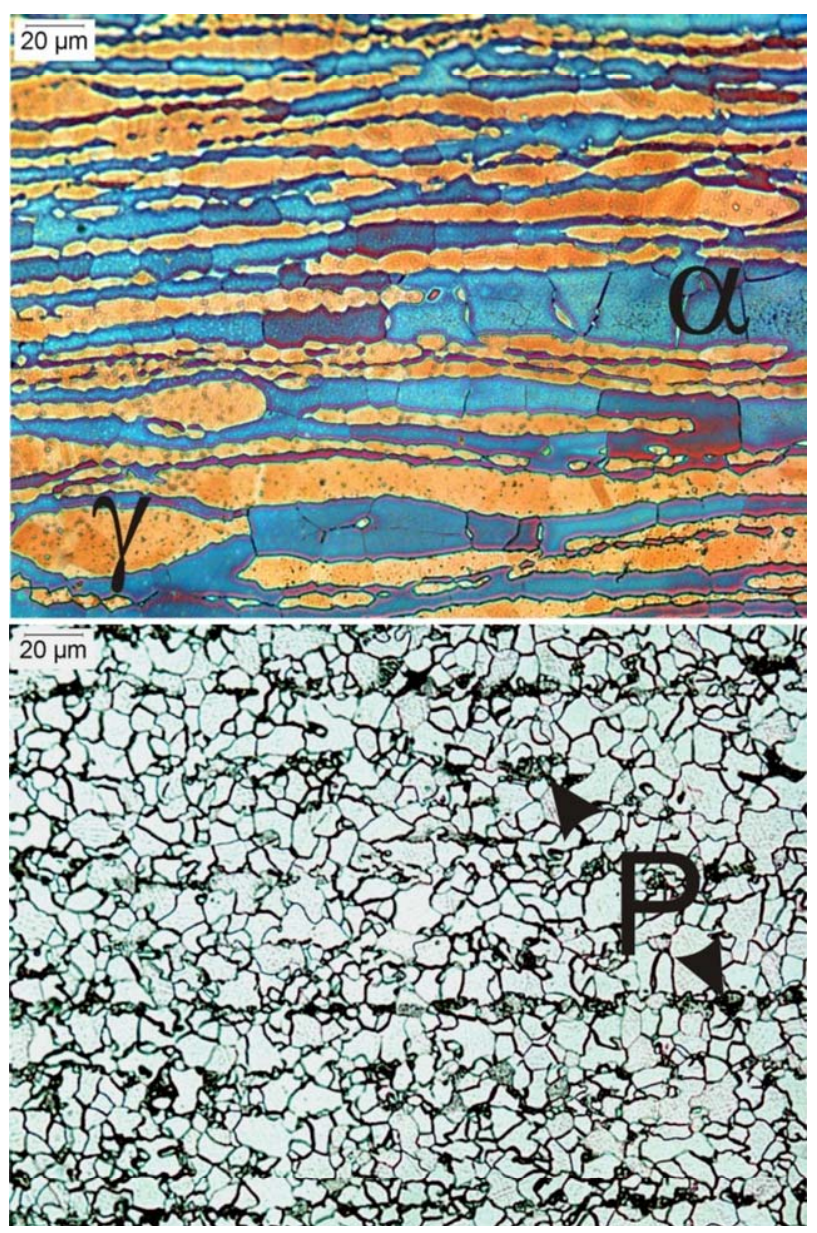

Figure 1. Microstructure of SAF 2507 and API X 52 in the as-received condition (magnification $40 \mathrm{X}$ ).

for $50 \%$ and $25 \%$ of dilution ratio respectively, but below values of $42 \%$ of dilution the solidification mode is changed from ferrite plus austenite to ferrite, for that reason it could be said that ER $25.10 .4 \mathrm{~L}$ filler metal showed a better microstructural equilibrium than ER 2209 filler metal and will present a low quantity of mar- tensite phase because of its lower percentage of manganese.

\subsection{Dissimilar Metal Welding}

To join the pipes of SAF 2507 /API X-52 was designed the single $\mathrm{V}$ groove preparation varying the bevel angle (60 and 90 degrees) and using the filler metal ER 25.10.4L with the aim of observing the effect of the thermal cycle promoted by the subsequent pass over the parent metals and previous passes.

To fill out the 60-deg dissimilar welding join, three welding passes were needed and five welding passes to fill out the DMW with 90-deg, as is shown in Figure 3. For each single pass the same heat input of $0.75 \mathrm{~kJ} / \mathrm{mm}$ was maintained. In Figure $\mathbf{3}$ is possible to observe the difference on the microstructures in function of the thermal cycles promoted by the welding passes, such effect could be noticed in the heat affected zone (HAZ) of the API X-52, where the phase transformation can be observed in function of the contrast, as well as the weld metal.

\subsection{Microstructural Characterization}

The microstructures in the DMW could be divided in three sections; HAZ API X-52, weld metal and HAZ SAF 2507 to observe the microstructural changes presented in each zone during the root, filler and cover pass. The HAZ-API X-52 in both welds presents solid phase transformations as observed in Figure 4, being those in the 60-deg weld, more notable, where can be distinguish the upper bainite (UB) which has a characteristic of feathery appearance as is shown in the cover and filler pass; widmanstätten ferrite (WF) and grain boundary ferrite (GF) are present in the root pass.

On the other hand, the microstructure on the 90-deg weld shows polygonal ferrite (PF) in the root pass and the filler passes but in the cover pass shows acicular ferrite (AF) and grain boundary ferrite.

The microstructural differences between both welds are in function of the weld pass number, due to each pass submitted the parent metals to different thermal cycles, or sometimes, the parent metal is reheated [16]. This is possible to observe if both root passes are compared.

In the 60-deg weld is possible to observe the WF and PF microstructures while in the weld with 90-deg only $\mathrm{PF}$ is observed.

This difference is the result of the subsequent weld passes which give different reheating and cooling rates, as is shown in the filler pass on the 90-deg weld where more weld passes were necessary to fill the join promoting that the temperature was more stable and therefore, causing slow cooling rates resulting in the same microstructure observed in the root pass. 


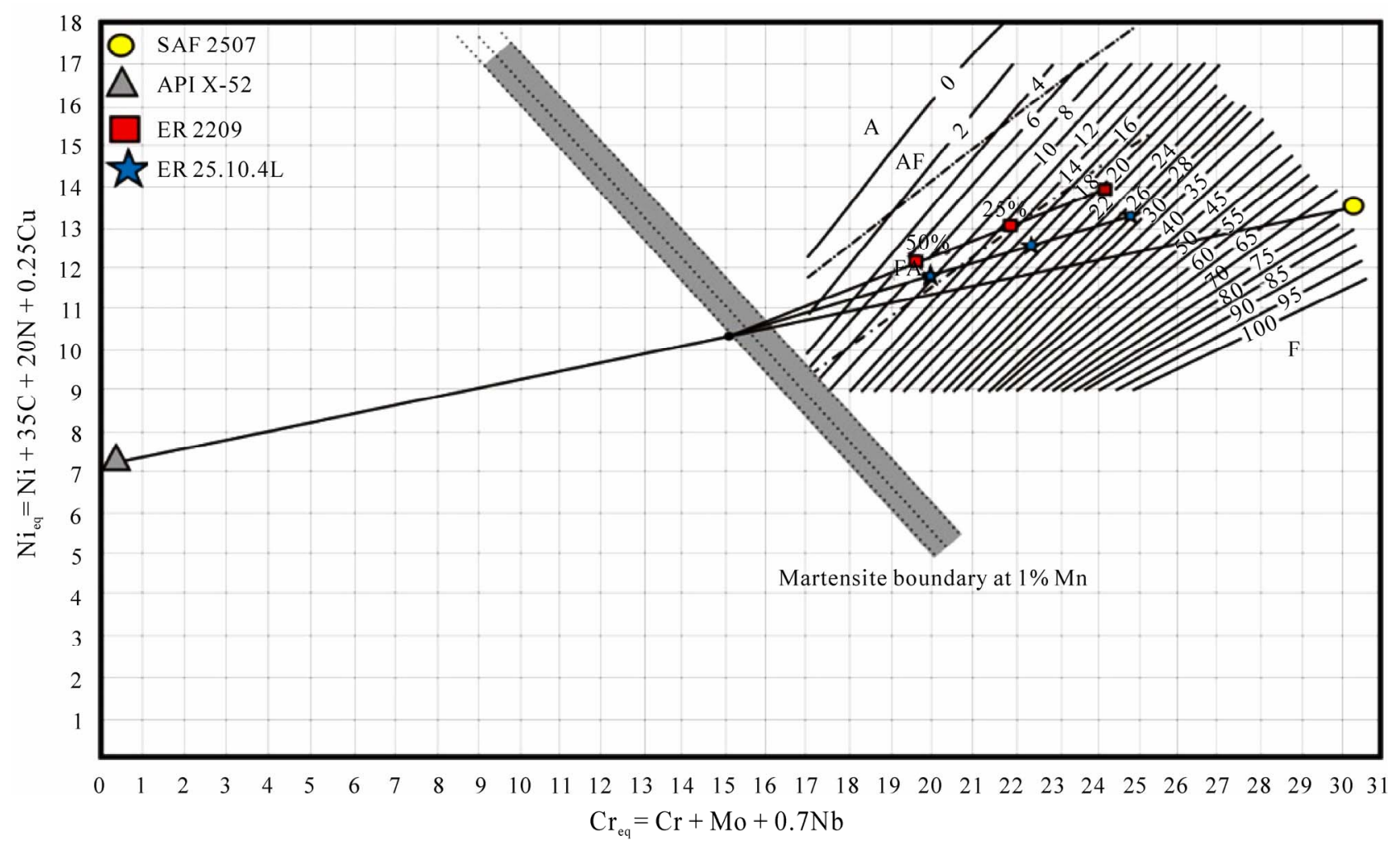

Figure 2. WRC-1992 diagram employed to select the filler metal.
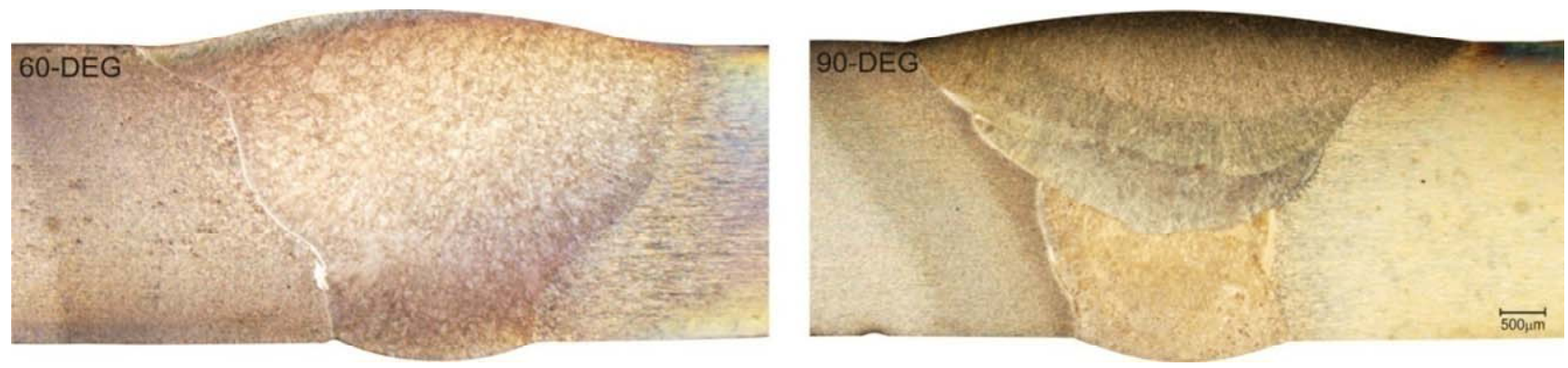

Figure 3. DMW with different number of welding passes.

The cover pass in both welds and filler pass in the weld with 60-deg showed the effect of the fast cooling which promotes the formation of upper bainite typical of cooling rates too fast for pearlite to form, yet not rapid enough to produce martensite [17].

It is important to denote the dramatic change in the microstructure where the narrow martensite band is present in the fusion boundary between the API X-52 and the weld metal which had been predicted by the WRC-1992 diagram modified by Kotecki to accurate the prediction of martensite phase in function of the manganese.

These microstructural changes in the dissimilar metal welds have been studied by Nelson and Lippold who established that dissimilar weld joints present solidification pattern type II, similar to the one present in Figure 5, where is clearly observed the suppression of normal epitaxial growth resulting in the formation of what are called boundaries type II, which run roughly parallel to the fusion boundary formed in the solid state during weld cooling when both the weld metal and HAZ are austenitic, allowing austenite grain growth in the fusion boundary. These boundaries may become sites for carbide precipitation, particularly if significant carbon migration from the base metal has occurred [15].

The microstructural changes in the weld metal of both dissimilar weld joints are shown in the Figure 6 where is possible to observe the difference in the root and cover passes due to the reformation of austenite, because the microstructure in the weld metal is controlled by two variables; the chemical composition of the filler metal and the thermal cycle of the weld process. 
60-DEG
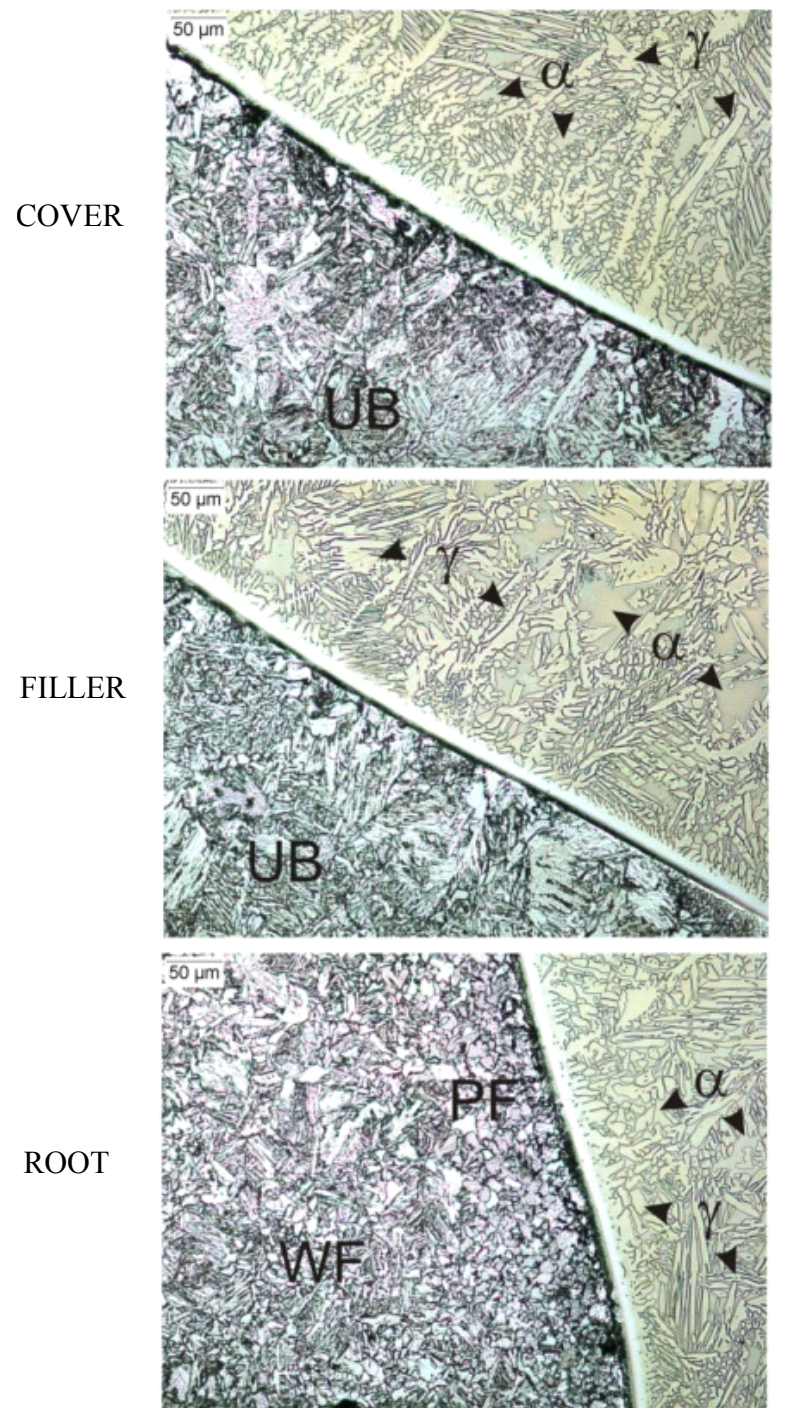

90-DEG
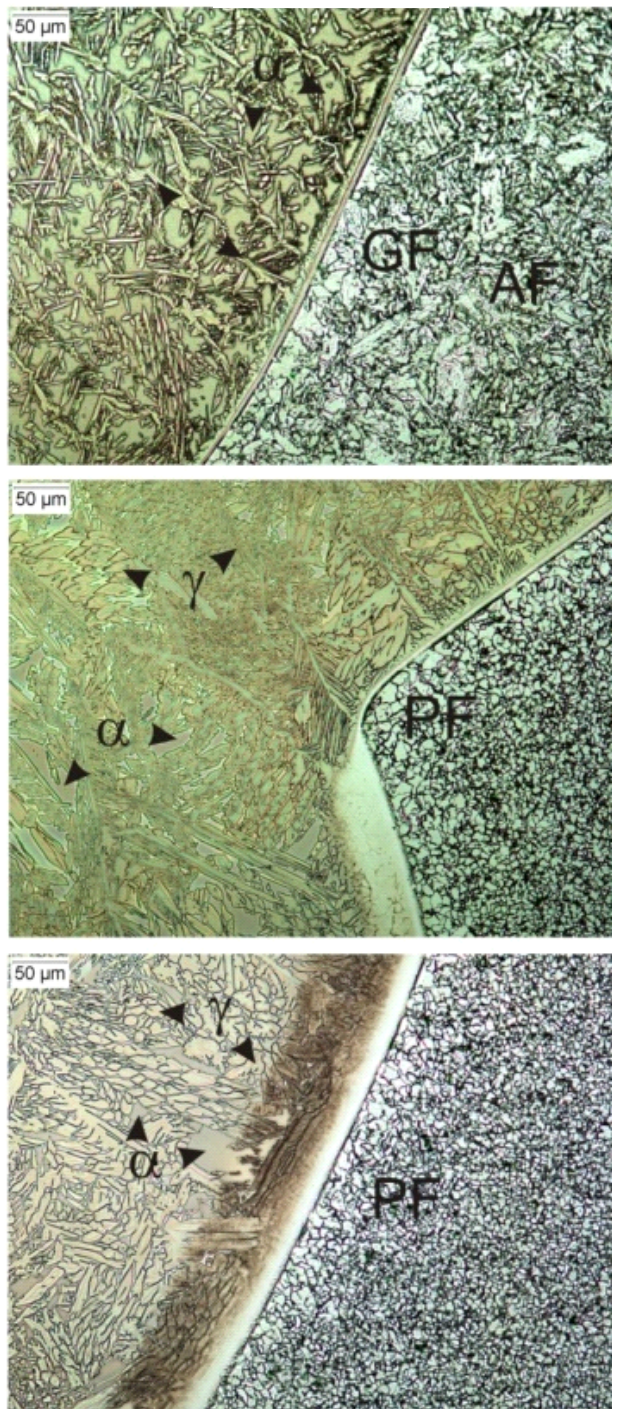

Figure 4. Transformations of solid phases in the HAZ APIX-52.

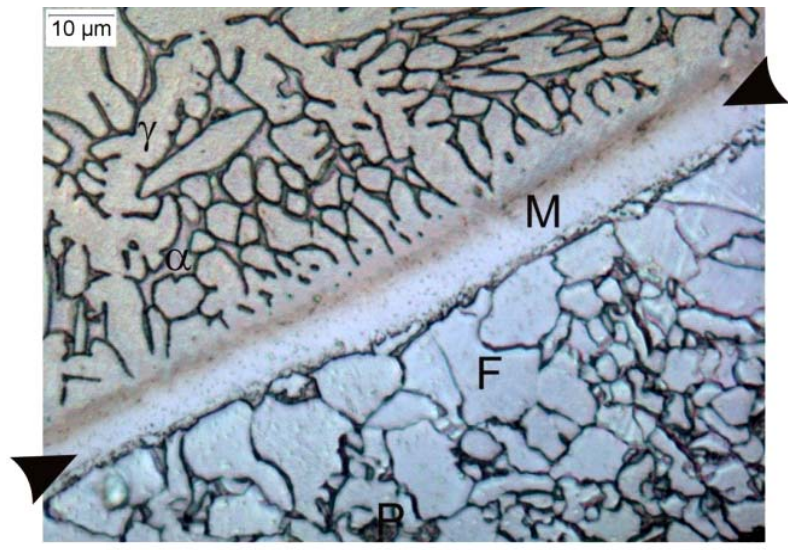

TYPE II

BOUNDARIES

Figure 5. Martensite band in the fusion boundary.
The first of them could be solved if the filler metal is selected correctly in function of the chemical composition which stabilizes the austenite phase with elements such as nickel and nitrogen, employing diagrams to predict the microstructure resulting of the mix of parent metals and filler metal. The thermal cycles promoted by the multipass welding can origin slow cooling rates, causing a diffusional transformation of ferrite to austenite where can be reached a favorable equilibrium between those phases. However, if the cooling is too slow in the reheated areas it could be found the precipitation of intermetallic phases [18].

The heat affected zone of the SAF 2507 present in both welds, where is possible to observe the zone where the austenite was diluted into the matrix, becomes in an entire ferritic structure. During this process some precipitates could be formed, followed of this process and 
60-DEG
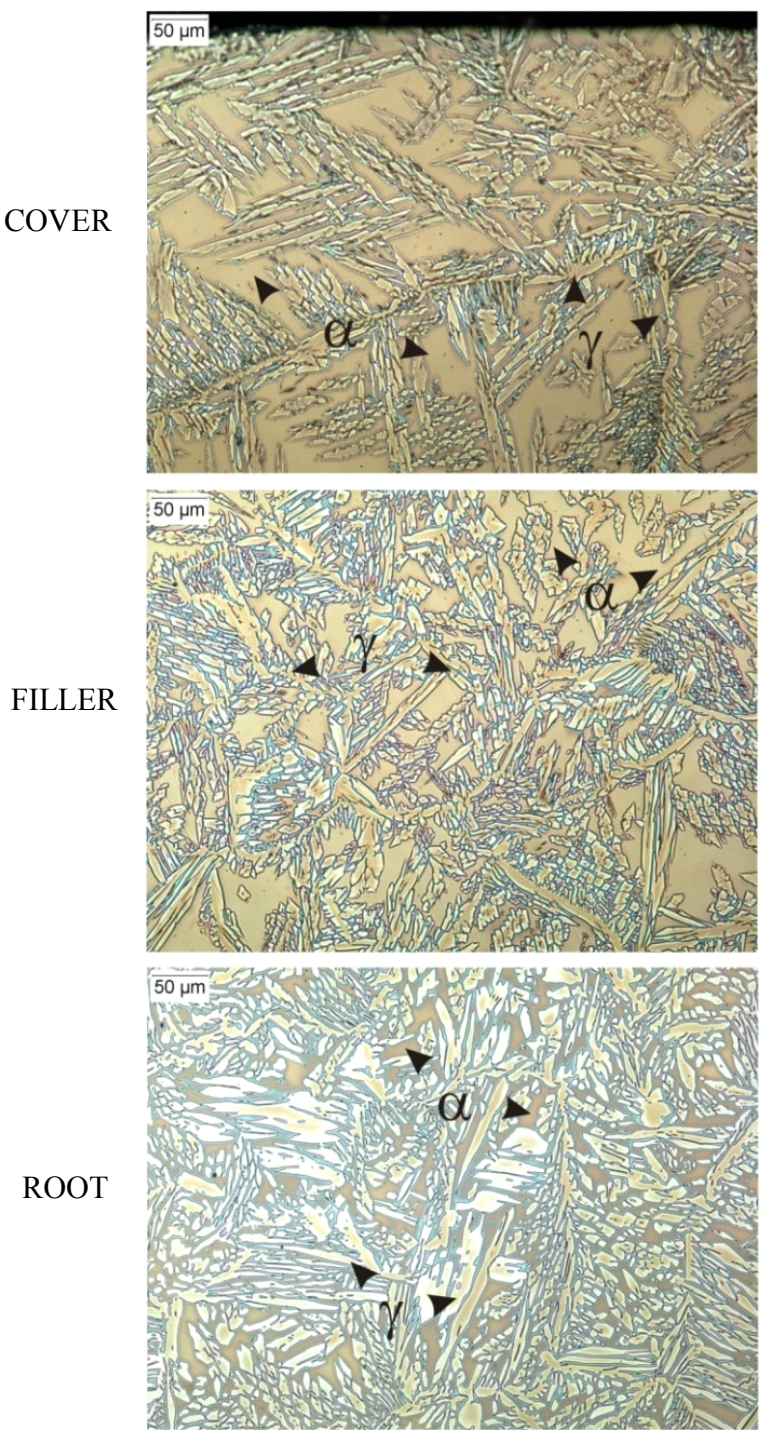

90-DEG
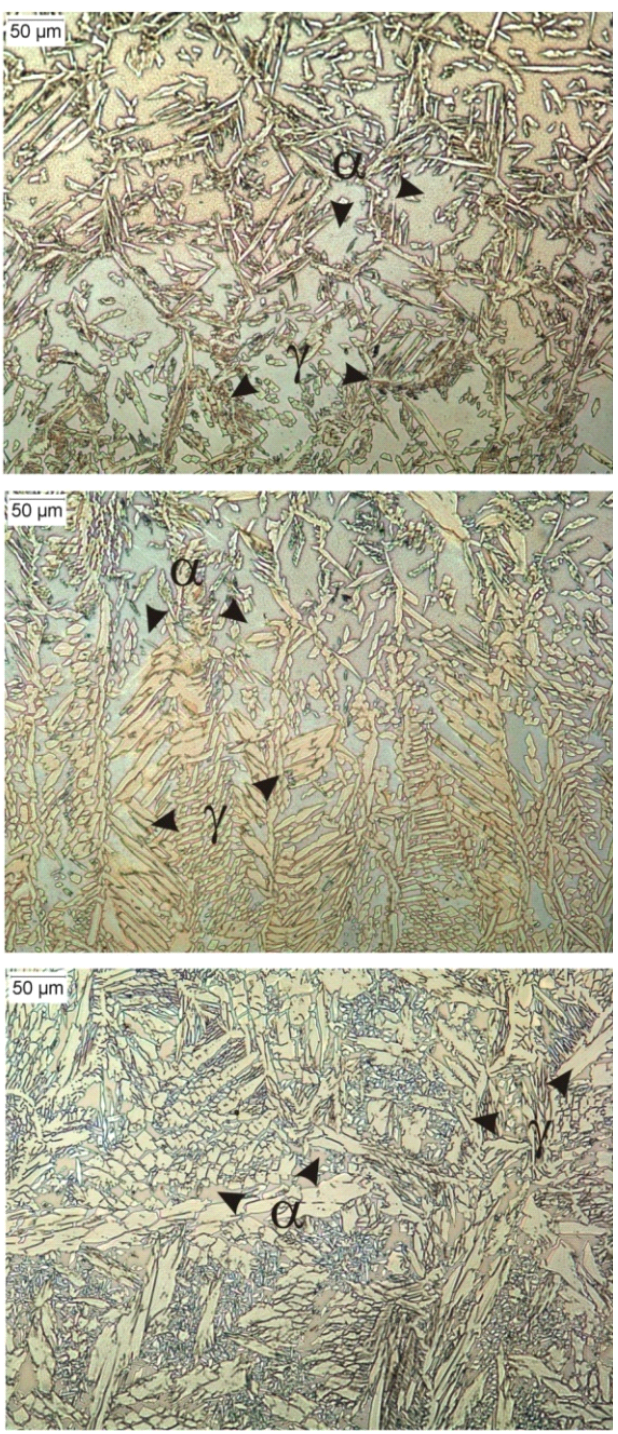

Figure 6. Austenite reformation in the weld metal.

above the temperature ferrite solvus, ferrite grain growth occurs since there is no second phase (austenite) or precipitates to inhibit such growth.

The multipass welding could maintain the parent metal above the ferrite solvus promoting the growth of the ferrite grains. During the cooling, when the temperature is below the ferrite solvus temperature, austenite will nucleate and grow and the precipitates will reform.

The ferrite-to-austenite transformation for a given alloy is controlled by the cooling rate. With higher cooling rates as is shown in the 60-deg weld where is possible to observe that the austenite reformation is suppressed and resulting in higher ferrite contents in the HAZ. The degree of precipitation is also a function of the cooling rate [15].

\subsection{Mechanical Properties}

The dissimilar welding joints were subjected to tensile test with the aim of knowing the ultimate strength and the behavior of the joint. Two tensile samples with standard dimensions were performed for each joint, obtaining values of ultimate strength of 541 and $533 \mathrm{MPa}$ for the 60-deg DMW and 531 and $556 \mathrm{MPa}$ for the 90-deg DMW.

All the values obtained from the tests were superior to the ultimate strength of the API X-52 in the as-received condition which is $455 \mathrm{MPa}$. The bend tests were applied to know the sanity of the joints due to the welding of duplex alloys, frequently present problems of cracks in the weld metal and in the HAZ because of the high ferrite content [19]. As is shown in Figures 6 and 7 the balance 
60-DEG
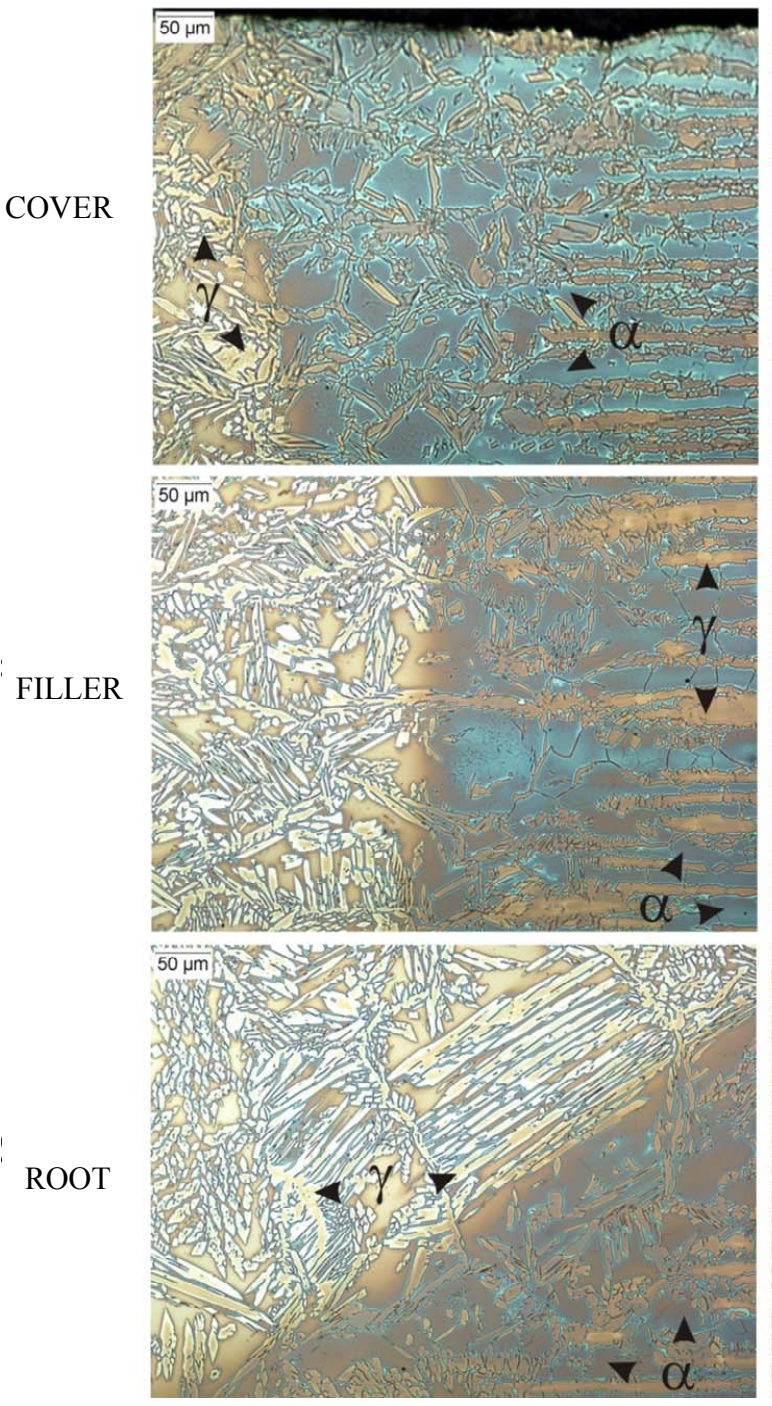

90-DEG
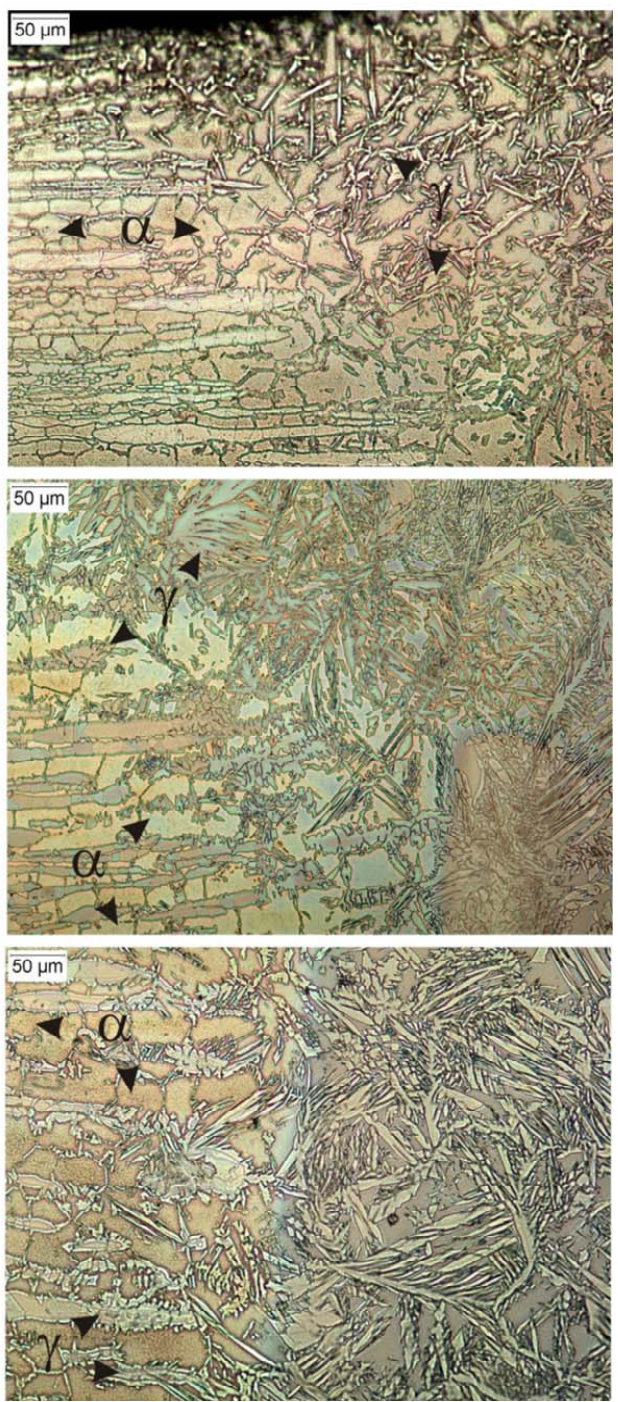

Figure 7. Heat affected zone in the SAF 2507.

of phases was adequate for that reason all the samples showed good performance in the root and face bends.

The microhardness Vickers was performed with the aim of knowing the effect of each phase in the dissimilar joint, as is shown in Figure 8.

In Figure 8 is possible to notice the effect of the martensite band on the increase of the hardness in the fusion boundaries followed by a hardness decreasing in the adjacent zone in both dissimilar welds which could be attributed to the phase transformations in that zone. Although the decrease of the hardness in that zone, the hardness values are higher than the hardness in the base metal API X-52.

\section{Conclusions}

The selection of the filler metal employing the WRC-1992 modified by Kotecki demonstrated to be accurate for dissimilar metal welding due to it can predict the martensite boundary and the microstructural balance between ferrite and austenite using the ER 25.10.4L filler metal which the chemical composition has low percentage of manganese and molybdenum but high percentage of nitrogen. The effect of the filler metal is clearly observed in the microstructure of the weld metal and HAZ where high austenite phase was obtained, but is important to consider the effect of the thermal cycles of the multipass weld which promotes the austenite reformation.

The HAZ of the API X 52 shows different transformation typical of that alloy when they are submitted to thermal cycles evolved a rapid cooling, which is the case of upper bainite phase.

However, the polygonal ferrite is obtained when the cooling rate is slow as presented in the reheated zones in 


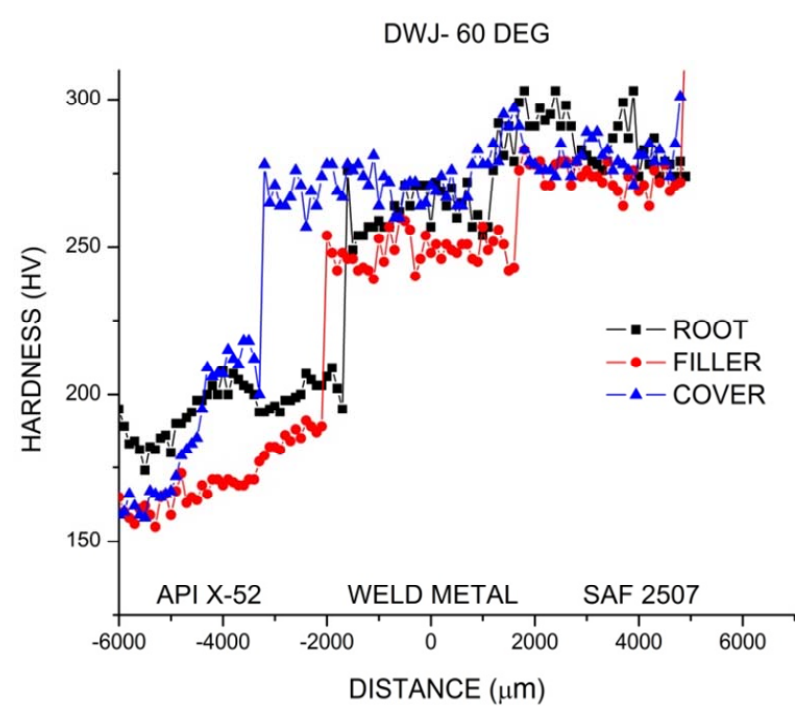

DWJ- 90 DEG

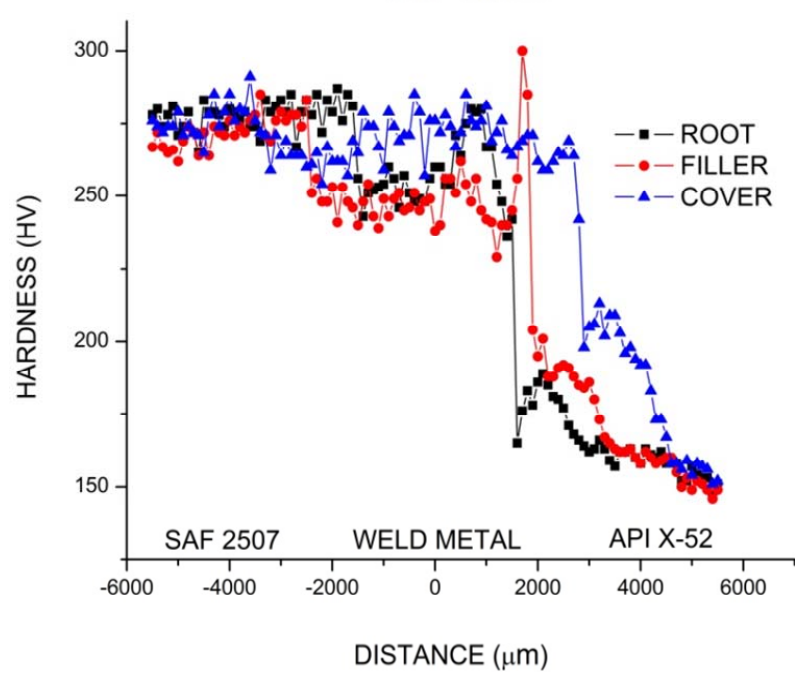

Figure 8. Microhardness profiles of the dissimilar metal welding.

the HAZ. The martensite showed in the fusion boundaries is formed when both alloys at high temperature present austenite phase and some atoms of carbon starts to diffuse from the API X-52 (with high concentration) to the weld metal (with lower concentration). Nevertheless some atoms during the cooling find the preferential place in the interface, which promotes the transformation to martensite phase. On the other hand the HAZ of the SAF 2507 SDSS is represented by the reformation of austenite phase in the zones where ferrite solvus temperature was reached, showing again the effect of the filler metal composition and thermal cycles of multipass welding.

The dissimilar welding joint showed higher resistance than the API X-52 base metal in the tensile test and good performance in the bend test, showing the soundness of the joint. The results demonstrated that the filler metal contributes to the austenite formation which gives those characteristics of behavior. The microhardness showed not only the clear difference between the alloys but also the effect of the phases, as the martensite phase.

\section{References}

[1] PEMEX, "Tubería de acero para recolección y transporte de hidrocarburos," NRF-001-PEMEX-2007 México, 2007.

[2] J. J. Perdomo, J. J. Gonzalez and A. Viloria, "Corrosion of API 5L and X52 in Crude Oil/Water/Gas Mixtures," Materials Performance, Vol. 39, No. 2, 2000, pp. 76-79.

[3] PEMEX, "Sistema de protección del ducto ascendente en la zona de mareas y oleaje," NRF-177-PEMEX-2007, México, 2007.

[4] O. Smuk, H. Hanninen and J. Liimatainen, "Mechanical and Corrosion Properties of P/M-HIP Super Duplex Stainless Steel after Different Industrial Heat Treatments as Used for Large Components," Materials Science and Technology, Vol. 20, No. 5, 2004, pp. 641-644.

[5] F. Elshawesh, N. Elahresh and A. Elhoud, "Effect of Sigma Phase on Pitting Corrosion 22-5 Duplex Stainless Steel," British Corrosion Journal, Vol. 33, No. 4, 1998, pp. 285-287.

[6] Y. H. Lee, K. T. Kim, Y. D. Lee and K. Y. Kim, "Effect of W Substitution on Sigma and Chi Phase Precipitation and Toughness in Duplex Stainless Steels," Material Science and Technology, Vol. 14, No. 8, 1998, pp. 757764.

[7] R. Francis, "Coupling of Super Duplex Stainless Steel and Cast Nickel-aluminium Bronze in Sea Water," British Corrosion Journal, Vol. 34, No. 2, 1999, pp. 139-145.

[8] A. A. El-Yazgi and D. Hardie, "Effect of Heat Treatment on Susceptibility of Duplex Stainless Steel to Embrittlement by Hydrogen," Materials Science and Technology, Vol. 16, No. 5, 2000, pp. 506-510.

[9] V. Amigo, V. Bonache, L. Teruel and A. Vicente, "Mechanical Properties of Duplex Stainless Steel Laser Joints," Welding International, Vol. 20, No. 5, 2006, pp. 361-366.

[10] V. V. D. Mee, H. Meelker and R. V. D. Schelde, "How to Control Hydrogen Level in (Super) Duplex Stainless Steel Weldments Using the GTAW or GMAW Process," Welding Journal, Vol. 78, 1999, pp. s7-s14.

[11] E. J. Barnhouse and J. C. Lippold, "Microestructure/Property Relationships in Dissimilar Welds Between Duplex Stainless Steels and Carbon Steels," Welding Journal, Vol. 77, No. 12, 1998, pp. s477-487.

[12] H. Hemmer and O. Grong, "A Process Model for the Heat-affected Zone Microstructure Evolution in Duplex Stainless Steel Weldments: Part I. The Model," Metallurgical and Materials Transaction A, Vol. 30A, No. 11, 1999, pp. 2915-2929.

[13] T. W. Nelson, J. C. Lippold and M. J. Mills, "Nature and Evolution of the Fusion Boundary in Ferritic-Austenitic 
Dissimilar Weld Metals, Part 1-Nucleation and Growth," Welding Journal, Vol. 78, No. 10, 1999, pp. s329-s337.

[14] D. J. Kotecki, "A Martensite Boundary on the WRC 1992 Diagram Part 2: the Effect of Manganese," Welding Journal, Vol. 79, No. 12, 2000, pp. s346-s354.

[15] J. C. Lippold and D. J. Kotecki, "Welding Metallurgy and Weldability of Stainless Steels," Jhon Wiley \& Sons, New Jersey, 2005.

[16] H. Granjon, "Fundamentals of Welding Metallurgy," Abington Publishing, Cambridge, 1991.
[17] H. K. D. H. Badeshia and R. W. K. Honeycombe, "Steels," 3rd Edition, Butterworth-Heinemann, Oxford, 2006.

[18] S. Henrik and R. Sandström, "Austenite Reformation in the Heat-affected Zone of Duplex Stainless Steel 2205," Materials Science and Engineering A, Vol. 418, No. 1-2, 2006, pp. 250-256.

[19] K. Bekker, "Practice in Welding Duplex and Super Duplex Stainless Steel Worldwide," Welding in the World, Vol. 36, 1995, pp. 111-123. 